\title{
Conceptual Metaphor Theory and Teaching of English and Chinese Idioms
}

\author{
Xiuzhi Li \\ School of Adult Education, Dezhou College, Dezhou, China \\ Email: lcdxlxz@163.com
}

\begin{abstract}
This paper talks about the relationship between conceptual metaphor and semantic motivation of English and Chinese idioms from three aspects, namely, structural metaphor, orientation metaphor and ontological metaphor. Based on that, the author puts forward applying conceptual metaphor theory to English and Chinese idiom teaching.
\end{abstract}

Index Terms - conceptual metaphor theory, semantic motivation, English and Chinese idiom

\section{INTRODUCTION}

Traditional view of idioms holds that idioms are not motivated and their formation is arbitrary. However, cognitive linguists shed new light on this problem. Cognitive linguists including Keysar and Bly (1999) suggest that some idioms make sense because they are motivated by conceptual structures that exist independently of language. Lakoff and Johnson (1980) argue that "the concept is metaphorically structured, and the activity is metaphorically structured, and, consequently, the language is metaphorically structured" (1980: 5). From the statements, we can perceive the metaphorical nature of language and pervasiveness of metaphors. Idioms as an important part of language also take on the feature of metaphor. Based on a large quantity of English and Chinese idiomatic expressions, we find that many idioms are generated from the underlying conceptual metaphors. In this thesis, the linguistic expressions refer to the idiomatic expressions or idioms as the study objects. The author aims at illustrating the cognitive motivations of English and Chinese idioms based on the conceptual metaphor theory, based on which the author will illustrate how to implement the teaching of cognitive motivation of English and Chinese idioms.

\section{CONCEPTUAL METAPHOR AND SEMANTIC Motivation OF IDIOMS}

According to the cognitive semantics, metaphor is no longer considered merely as an ornamental device that is restricted to literature and poetry. They nonetheless are part of our knowledge of how people talk about abstract concepts, and play a role in our comprehension of figurative expressions about these concepts. The major contribution of the CMT (Conceptual Metaphor Theory) is that conceptual metaphor enables us to organize metaphorical expressions, including idiomatic expressions in a systematic way. The conceptual metaphor hypothesis assumes that many motivated idioms are based on conceptual metaphors. Lakoff and Johnson (1980) distinguish three fundamental types of conceptual metaphors: structural, orientational, and ontological. In the following sections, the three types will be discussed respectively as to how they are related to the motivation of idioms.

\section{A. Structural Metaphor and Idioms}

A structural metaphor refers to a conceptual metaphor that is constructed from one conceptual structure to another. In other words, in structural metaphor, one concept is understood and expressed in terms of another structured, sharply defined concept. With the help of the structural metaphor, we can use the words concerning one concept to talk about another concept. For instance, war is a concept that is frequently mapped onto the target domains such as argument and love. As we know, war is a concrete concept that we are very familiar with, so we often talk about argument and love in terms of war. Everyone knows that war is a very complex process that involves plan, attack, defense, counterattack, fight, win, lose, truce etc. Argument and love are all complex and abstract concepts. As a result, the knowledge of war can be used to talk about the unknown abstract concepts, that is argument and war, because they share many similarities. Consequently, we have idioms motivated by the structural metaphors ARGUMENT IS WAR. Let's first look at some idioms motivated by the structural metaphor ARGUMENT IS WAR:

(1) Criticisms were right on target.

(2) Shot down all of my arguments.

(3) Is he not entitled to hit back?

(4) wu di fang shi (shoot an arrow without a target; speak or argue without purpose)

(5) chun qiang she jian (cross verbal swords; intense debate)

(6) she zhan qun ru (tongue beat a group of intellectuals; debate with group of intellectuals and win)

(7) yan cifeng rui (sharp words; intense debate)

In the above idioms, we can see that words in war such as target and shot are mapped onto argument in (1) and (2); 
hit back onto argument in (3); di (target) onto argument in (4); qiang (gun) and jian (arrow) onto argument in (5); zhan (beat) onto argument in (6); feng rui (sharp) onto argument in (7). This is an example of what it means for a metaphorical concept, namely, ARGUMETN IS WAR, to structure (at least in part) what we do and how we understand what we are doing when we argue. Arguments and wars are different kinks of things and the actions performed are different kinds of actions. But we can use our knowledge about war to understand and talk about argument. Here, war is the source domain, and argument is the target domain. Therefore the knowledge from the source domain is mapped onto the target domain. Thus the understanding of argument.

\section{B. Orientational Metaphor and Idioms}

Unlike the structural metaphors, orientational metaphors do not structure one concept in terms of another but instead organizes "a whole system of concepts with respect to one another" and "Spatial orientations arise from the fact that we have bodies of the sort we have and that they function as they do in our physical environment" (Lakoff \& Johnson, 1980:14). In the following parts, I will take up/down orientation as an example to illustrate how orientational metaphors can motivate idiomatic expressions.

GOOD IS UP; BAD IS DOWN

Lakoff \& Johnson mentioned "the physical basis for personal well-being: happiness, health, life, and control-the things that principally characterize what is good for a person-are all up" (1980: 16). Let's look at the examples of idioms motivated by this orientational metaphor.

(1) Things are looking up.

(2) It's polite to yield up your seat on the bus to an old lady.

(3) Bernard has fallen on evil days since he lost his job and his wife left him.

(4) He lives down and out.

(5) li zheng shang you (aim high; strive for the first place)

(6) zheng zheng ri shang (becoming more prosperous every day; flourishing)

(7) gan bai xia feng (to be willing to play second fiddle; to candidly admit defeat)

(8) mei kuang yu xia (go from bad to worse)

All in all, the above mentioned UP/DOWN metaphors can motivate many idioms both in English and Chinese describing such abstract concepts as good and bad. Such metaphorical orientations are not arbitrary. They have a basis in our physical and cultural experience. This view is supported by Wang Yin as following: What do we experience? Of course it is our body. What is the first thing we experience? It is the space which includes place, orientation and movement. So the experience of the body and space is the origin of human concepts and language. Human's cognition is based on the understanding of their bodies and space, developing from far to near, from concrete to abstract, from the domain of body and space to other domains (Wang Yin, 2005: 50).

\section{Ontological Metaphor and Idioms}

Our experience of physical objects and substances provides a further basis for understanding — one that goes beyond mere orientation. Understanding our experiences in terms of objects and substances allows us to pick out parts of our experience and treat them as discrete entities or substances of a uniform kind. Container metaphor is the most typical kind of ontological metaphors. We are physical beings, bounded and separated from the rest of the world by the surface of our skins, and we experience the rest of the world as outside us. "Each of us is a container, with a bounding surface and an in-out orientation. We project our own in-out orientation onto other physical objects that are bounded by surfaces" (Lakoff \& Johnson, 1980: 29). Thus we also view them as containers with an inside and an outside. Let's look at examples from Chinese and English idioms:

(1) He is out of sight.

(2) We're out of trouble now.

(3) He fell into a depression.

(4) She fell in love with him.

(5) zhi shen shi wai (to be out of things)

(6) zhui ru qing wang (fall in love with)

In the above examples, sight, trouble, depression, love in English and shi (things) and qing (love) in Chinese are all abstract concepts which are metaphorically viewed as concrete concepts bearing boundaries. According to our subconscious knowledge, the meaning of these idioms can be grasped easily. In example (1) from the literal meaning "out of sight", we can get the metaphorical meaning "can not see anything".

\section{USE OF CONCEPTUAL METAPHOR THEORY IN IDIOM TEACHING}

According to Kǒvecses \& Szabo's experiments, the teaching effect is much better when the cognitive motivation teaching is adopted in idiom teaching and learning. However we should not abandon the traditional method completely. Conceptual metaphor teaching method can be treated as an effective complement in idiom teaching and learning, for not all idioms are semantically motivated just as mentioned earlier. Concretely speaking, we can do from the following aspects. 


\section{A. Improving Teachers'Metaphorical Competence}

If we want to apply the conceptual metaphor theory to idiom teaching and learning, we should improve teachers' metaphorical competence in the first place, for teachers are the practical implementer of the theory. Both English and Chinese teachers should grasp the conceptual metaphor theory expertly and be good at summarizing the new conceptual metaphors they encounter during the teaching process. Lakoff and Johnson can not generalize all of the conceptual metaphors that meet the needs of idiom teaching and learning because language is undergoing changes continually. This situation puts forward severe challenges for both English and Chinese teachers. Therefore, schools should make every effort to provide opportunities for teachers to further their study of metaphor theory. Only in this way can we laid a solid foundation for the cognitive motivation teaching of idioms.

During the teaching practice process, teachers should make it clear to students how a series of idioms are related to their conceptual metaphor motivation accordingly. Moreover based on the conceptual metaphor motivation, teachers need to encourage students to deduce the metaphorical meaning of idioms, but not list the idioms together simply. Otherwise the desirable teaching results can not reach. Let's take the conceptual metaphor ANGER IS THUNDER as an example. Both in English and Chinese, there exists a minor structural metaphor ANGER IS THUNDER. An angry person reminds both English and Chinese people of a natural phenomenon-thunder, as they are equally alerting and threatening. Moreover, by comparison we find some idiomatic expressions in both languages motivated by this structural metaphor. The following examples can illustrate this point:

\section{ANGER IS THUNDER}

(1) When I stood up to him, his face was as black as thunder.

(2) He scolded his son, with a face like thunder.

(3) da fa lei ting (burst into a rage)

(4) bao tiao ru lei (stamp with rage)

(5) lei ting zhi nu ( so angry just as powerful as a thunderbolt)

Seen from the above example, the teacher can give students conceptual metaphor ANGER IS THUNDER first, which is used to express one emotion "anger" both in English and Chinese. Next, teachers should explain the relation between the conceptual metaphor and the series of idioms such as " black as thunder; with a face like thunder; da fa lei ting; bao tiao ru lei ; lei ting zhi nu". Moreover, it is necessary for teachers to encourage students to guess the idioms' meaning according to the given conceptual metaphor ANGER IS THUNDER. It can be easily inferred that the above mentioned idioms all mean "very angry" generally speaking.

\section{B. Cultivating Students' Metaphorical Awareness}

In the ordinary teaching activities, teachers should cultivate students' metaphorical awareness consciously. Concretely speaking, teachers should carry out the job from two aspects. For one thing, teachers should make students know that metaphors are not only considered to be poetical or rhetorical embellishments, but "in essence, a means of understanding and experiencing one kind of thing in terms of another" (Lakoff\&Johnson, 1980: 42). In brief, metaphor "is a cross domain mapping in the conceptual system" (Lakoff, 1993: 203). Since "one reflection of our conceptual system is language" (Kǒvecses, 1986: 3), thus "language is virtually metaphorical" (Richards, 1967: 80). Therefore, metaphors are a part of everyday speech that affects the ways we perceive, think, and act- they are pervasive in language and systematic. For another, teachers should instruct students to command the analytical method of metaphors, cultivate their ability to think and learn independently. In the daily teaching process, teachers should make the best use of the teaching time in class to foster students' analysing ability when meeting metaphors in textbooks. As for the idioms appearing in textbooks, it is necessary for teachers to encourage students to dig out the underlying conceptual metaphor system of idioms. This method helps deepening the understanding of knowledge about target language, thus promoting the learning of English accordingly. Let's take the following English and Chinese idioms as example.

(1) He hung down his head hearing the news he failed the exam.

(2) He has been in low spirits these days.

(3) He brought me down with his remarks.

(5) I fell into a depression.

(6) He has been feeling down lately.

(7) chui tou sang qi (downcast; in low spirits; depressed)

(8) yi jue bu zhen (to collapse after one setback)

(9) wei mi bu zhen (drooped; in low spirits; dejected)

Seen from the above examples, we can see that the words "down, low, fell, chui; jue and wei mi" are all closely related to the concept "down" (xia). Therefore, both English and Chinese adopt the same orientational metaphor SADNESS IS DOWN to indicate the sadness emotion. So the source domain is orientation "down" (xia) and the target domain is sadness emotion. The similarity lies in the fact that drooping pictures goes along with the negative emotions, such as sadness and depression, while erect posture with a positive emotional state such as happiness we mentioned in the previous sections. In a word, the same physical and psychological basis of human beings leads to the same orientational metaphor SADNESS IS DOWN describing the sadness emotion. Furthermore some idioms are generated motivated by this orientational metaphor. 


\section{Inputting Relevant Cultural Background}

To a large extent, Conceptual metaphors depend on the commonness of human being's metaphorical mode of thinking. However, like common metaphors, sometimes they take on the obvious characteristics of national culture. That is nationality (Zhang Guangming, 2002: 165). Lado has once stated that significant differences are the blind spots of foreign language learning. Moreover, cultural differences will lead to the differences of conceptual metaphors. Different living environments, geographical locations, world views and religious beliefs etc are the main reasons that cause cultural differences of conceptual metaphors. As a result, it is rather necessary for teachers to explain the relevant cultural background to students. For example, despite the fact that both in English and Chinese there exists the same container metaphor ANGER IS FIRE. However, it has two versions. One is ANGER IS A HOT FLUID IN A CONTAINR existing in English, and the other is ANGER IS THE HOT GAS IN A CONTAINER belonging to Chinese. By careful analysis, we find some idiomatic expressions motivated by the two container metaphors respectively. Now let's look at some of them:

\section{ANGER IS A HOT FLUID IN A CONTAIENR in English}

(1) His pent-up anger welled up inside him.

(2) Don't get all steamed up over nothing.

(3) You make my blood boil.

(4) I had reached the boiling point.

(5) I was boiling with anger.

(6)He gave vent to his anger.

(7) He is just letting out steam.

(8) When he heard she was going to quit school, he simply blew up.

(9) Simmer down.

(10) He blew up his top.

(11) She flipped her lid.

(12) He hit the ceiling.

ANGER IS THE HOT GAS IN A CONTAINER in Chinese

(13) nu qi chong tian (in a towering rage)

(14) gan qi yu jie (be irritable)

(15) $n v$ qi chong chong (in a dudgeon; very angry)

(16) qi ji bai huai (flustered and exasperated)

(17) qi chong niu dou (be infuriated)

Now let's turn to the question why English employs the FLUID metaphor while Chinese conceptualizes anger in terms of GAS. The reason mainly lies in the cultural differences between China and western countries. Stanli, a philosopher in the ancient west, considers water to be the source of the universe. Therefore, it is no wonder that in English anger is compared to FLUID in a container, thus the conceptual metaphor ANGER IS A HOT FLUID IN A CONTAIENR and idioms based on it. On the contrary, ancient Chinese philosophers believe that human beings are the outcomes of the cosmos, whose origin and impetus of evolution is mainly the Qi (air; gas). And the philosopher Wang Chong in the East Han Dynasty says that all things in the universe have evolved from Qi. Moreover, the Chinese traditional medicine also has influence on GAS metaphor of anger. In the oldest Chinese medical work, <Huang Di's Orthodox Medical Classic>, it is pointed out that all diseases originate from the malfunctions of Qi. Qi is so pervasive in Chinese culture and language that we find many idioms associated with Qi just as illustrated in the above examples (13)-(17).

We can also explain why Chinese language prefers "Qi" but not "Fluid" in anger metaphor with another important theory in Chinese classical philosophy - Yin Yang Theory. According to this theory, all the things in the universe are generally divided into two categories: Yin and Yang, which are mutually promoted, restrained and are interchangeable. The Qi (air) and fire belong to the category Yang which is related to "hot"; water and other fluids fall into the category Yin which is connected with "cold". Therefore it's easier to understand why the Chinese choose fire and Qi (air) as the metaphorical concept for anger, while English choose fire and hot fluid, because in English there is no such conceptual system about air.

\section{CONCLUSION}

All in all, most English and Chinese idioms are motivated by conceptual metaphor in a systematic way, therefore, they can be analysed, which makes it feasible for the conceptual metaphor theory to be used in idiom teaching and learning. However, we mustn't abandon the traditional teaching method completely. We can treat the conceptual metaphor teaching method as an effective complement to accelerate the teaching and learning of idioms.

\section{REFERENCES}

[1] Keysar, B \& Bly, B. M (1999). Swimming against the current: do idioms reflect conceptual structure? Journal of Pragmatics 31,1559-1578. 
[2] Lakoff, G. \& Johnson (1980). Metaphors we live by. Chicago: University of Chicago Press.

[3] Wang Yin (2005). Exploration of cognitive linguistics. Chongqing: Chongqing Press.

[4] Lakoff, George (1993). The contemporary theory of metaphor. In Andrew Ortony (eds). Metaphor and thought. Cambridge: CPU, 202-251.

[5] Kǒvecses, Z (1986). Metaphors of anger, price, and love: A lexical approach to the structure of concepts. Amsterdam and Philadelphia: John Benjamin Publishing Company.

[6] Richards, J. C (1967). The role of vocabulary teaching. TESOL Quarterly, 10, 77-89.

[7] Zhang Guangming. (2002). Comparison of English and Chinese rhetoric thought and translation. Beijing: Beijing Yiwen Press.

Xiuzhi Li was born in Dezhou, China in 1972. She received her M. A degree in English Language and Literature from Liaocheng University, China in 2009.

She is currently a lecturer in the School of Adult Education, Dezhou University, Dezhou, China. Her research interests include foreign language teaching and research and cognitive linguistics. 